\title{
O SENTIDO DA POLÍTICA EM HANNAH ARENDT
}

Ana Paula Repolês TORRES ${ }^{1}$

- RESUMO: Buscamos demonstrar que a ação política, na visão de Hannah Arendt, não é meio para atingir qualquer fim, sendo sinônimo de liberdade, o que faz com que a autora problematize a tradicional identificação da política com violência, a partir de uma crítica ao equacionamento, que remonta aos primórdios do pensamento filosófico sobre o tema, de liberdade e vontade, fazer o que se deseja, o que leva a pensadora em questão a trabalhar as duas dimensões da ação política, isto é, a dimensão agonística e a consensualista, significando esta última uma liberdade mutuamente garantida.

- PALAVRAS-CHAVE: política, liberdade, violência, pluralidade.

Jamais existiu um governo baseado exclusivamente nos meios da violência.

(Hannah Arendt)

Após Dachau, Auschwitz, os Gulags siberianos, em síntese, depois das experiências totalitárias nazista e stalinista, qual o significado da política? Partindo de uma constatação arendtiana de que ação política é sinônimo de liberdade, será que podemos admitir como "política" programas de desumanização, de eugenia, isto é, de objetivação do homem? Será que a "política totalitária" (ARENDT, 1990, p.514), responsável pela transformação da própria natureza humana, por tornar possível o mal radical, absoluto e im-

1 Doutoranda em Filosofia pelo Programa de Pós-Graduação em Filosofia da Universidade Federal de Minas Gerais-UFMG sob orientação de Newton Bignotto de Souza e com auxílio da Fapemig. Artigo recebido em set/07 e aprovado em dez/07. 
perdoável, não ocultaria, em realidade, ações não-políticas, até mesmo antipolíticas? Não há contradição no próprio termo "política totalitária"? Por outro lado, será que a "politização" plena realizada por tais regimes totalitários e a concomitante e paradoxal extinção do espaço de liberdade necessariamente nos conduz a dar razão aos liberais, a entender como incompatíveis liberdade e política, só surgindo a primeira quando a última cessa de existir? Em outros termos, será que a política se restringe ao estatal e a liberdade possui somente uma dimensão negativa, uma liberdade a-política de "ter", de "crer", enfim, uma "liberdade da política" (ARENDT, 2001, p.195)? Tais indagações nos levam, com Arendt, a formular a seguinte questão: "Tem a Política ainda algum sentido?" (ARENDT, 2006, p.38). O que de fato é a política?

Ocorre que a perplexidade diante das catástrofes do século XX, bem como a constatação de que a destruição total, a eliminação da Humanidade e de toda vida orgânica da face da Terra é uma possibilidade real, fez não só com que se questionasse o que representa uma decisão "política" em uma guerra de extermínio, mas principalmente reforçou uma já tradicional aversão pela política, o anseio por uma ilusória extinção da mesma. Dessa forma, pode-se dizer, seguindo o desenvolvimento dos argumentos de Arendt, que o fato da "política" ter levado à desumanização completa dos indivíduos nos campos de concentração e de ter como resultado possível a extinção do fenômeno humano está por detrás dos preconceitos contra a mesma nas sociedades atuais, pois na medida em que política é identificada com violência, com domínio desenfreado de uns sobre outros norteado por interesses egoístas e mesquinhos, na medida em que se tem por evidente que "todo poder corrompe e que o poder absoluto corrompe ainda mais", ${ }^{2}$ a passividade, a apatia dos indivíduos, a renúncia ao exercício da cidadania, têm sido cultivadas, nas palavras de Arendt, essa "condenação do poder" corresponde a um "desejo inarticulado das massas" e tem gerado a "fuga à impotência" (ARENDT, 2006, p.28).

Partindo então do pressuposto, baseado no pensamento de Hannah Arendt, de que a política não é domínio, de que não se baseia na distinção entre governantes e governados e nem é mera violência, mas ação em comum acordo, ação em conjunto, sendo reflexo da condição plural do homem e fim em si mesma, já que não é um meio para objetivos mais elevados, como, por exemplo, a preservação da vida, significando liberdade, somos levados a perguntar se esses juízos naturalizados não seriam falsos e perigosos, isto é, será que ao se desconhecer a "verdadeira política", ao se

2 "Power tends to corrupt and absolute power corrupts absolutely" (ACTON apud ARENDT, 2006, p.200). 
confundir "aquilo que seria o fim da política com a política em si" (ARENDT, 2006, p.25) não estaria sendo disseminado o imobilismo, um sentimento de inutilidade de qualquer ação, fazendo com que o homem não se reconheça como um sujeito histórico, como um ser capaz de interromper o fluxo inexorável dos acontecimentos? Aceitar que a política não possui um sentido não equivaleria negar significado à nossa própria existência, não nos reduziria a autômatos guiados por algum anão oculto, como "o jogador de xadrez de Maelzel" do conto de Edgar Allan Poe citado por Benjamin, ou, nos termos de Kant, não nos tornaria indistintos dos animais, já que determinados pelas necessidades da natureza e incapazes de iniciar uma cadeia causal por nós mesmos?

Ocorre que, como indicamos acima, esses preconceitos não são novos, havendo toda uma tradição de identificação da política com domínio, com violência, cuja origem remonta à desvinculação entre política e liberdade realizada pelos filósofos que primeiro trataram do tema, em clara oposição à experiência da pólis grega. Nesse sentido, Arendt ressalta que não havia sequer o interesse pelo problema da liberdade na Antiguidade, tendo o mesmo surgido tardiamente na filosofia, com Epicteto, como uma forma do eu se relacionar com uma realidade externa que lhe seria adversa, resultando então de um estranhamento do mundo. Assim, a liberdade é pensada como interioridade, sendo este o único meio daqueles que não possuíam um lugar no mundo "sentirem-se livres", o que possibilitava aos homens serem escravos e livres ao mesmo tempo. Mais especificamente, podemos dizer que a liberdade em Epicteto resume-se a ser livre dos próprios desejos, a desejar somente aquilo que se pode obter, em oposição à concepção de que liberdade seja fazer tudo o que se deseja.

A partir de então, Arendt visualiza todo um desenvolvimento do conceito de liberdade a partir do conceito de vontade, remetendo-se assim ao pensamento cristão de Paulo e Agostinho, os quais também localizaram no espaço interior da consciência o problema da liberdade, dessa forma, esta última, ao invés de ser compreendida como a possibilidade de trazer ao mundo algo que não existia, passa a ser identificada ao livre-arbítrio, a uma escolha entre duas alternativas dadas. Trata-se, no sentido agostiniano, de um antagonismo dentro da própria vontade, de um querer e um não querer ao mesmo tempo, entre querer e não fazer, sendo a vontade poderosa e impotente, pois é, ao mesmo tempo, quem dá as ordens e quem não as obedece. Segundo Arendt, essa aproximação de liberdade e vontade pode ser elencada como "uma das causas pelas quais ainda hoje equacionamos quase automaticamente poder com opressão ou, no mínimo, com governo sobre outros" (ARENDT, 2001, p.210). Entretanto, de toda essa digressão o que nos interessa é a perda da concepção política de liberdade, do entendimento de que a liberdade não pode ser obtida na solidão e que não se resume ao 
"quero", mas que também necessita do "posso", em outros termos, podemos dizer que liberdade não significa fazer o que se deseja, não significa soberania, pois só se é livre perante outros que também o sejam.

Liberdade entre iguais foi justamente no que se baseou a pólis grega, pois diferentemente do âmbito doméstico onde reinava o despotismo e a desigualdade, do espaço privado destinado à satisfação das necessidades da vida, onde era justificada a violência e natural o domínio de uns sobre outros, do pai sobre esposa, filhos e escravos, a pólis surge como um espaço onde a distinção entre governantes e governados não fazia sentido, onde todos aqueles que igualmente obtiveram libertação das necessidade vitais podiam tornar-se livres, podiam participar e construir um mundo comum através de feitos e palavras. Desse modo, percebe-se que a liberdade não era obtida no relacionamento do eu consigo mesmo, mas sim na interação com seus semelhantes, pressupondo tanto a presença de outros "eus", quanto a existência de um espaço público organizado que permitiria a todos os homens livres "aparecer", isto é, agir.

Compreende-se, então, porque Arendt considera a liberdade e a ação política como sinônimas, haja vista que não é enclausurando-se em si mesmo, utilizando-se unicamente da capacidade de pensar ou de querer, que um indivíduo passa a ser livre, a liberdade existe onde a condição plural do homem não seja desconsiderada, sendo nada mais que ação, em outras palavras, o indivíduo só é livre enquanto está agindo, nem antes, nem depois. Ressalte-se, todavia, que a ação política só pode ser entendida como liberdade se a mesma não sofre qualquer forma de funcionalização, de instrumentalização, como a presente nas atividades do labor e do trabalho, ${ }^{3}$ cujo valor não estaria, ao contrário da ação política, no desempenho em si mesmo, mas sim em algum resultado, um fim a ser alcançado quando termina o processo produtivo. Tal como as artes de realização, como a música, a dança, o teatro, a ação política é valorada pelo seu "virtuosismo", entendido es-

3 Em A Condição Humana, livro realizado a partir de uma série de conferências proferidas na Universidade de Chicago em 1956, sob o nome de Vita Activa, Arendt realiza a distinção entre as atividades do trabalho (labor), da obra ou fabricação (work) e da ação (action), utilizando-se para tanto de uma análise da durabilidade dessas diferentes atividades, bem como da correspondência das mesmas com distintas condições humanas, a vida, o pertencer-ao-mundo ou mundanidade e a pluralidade. Assim, o trabalho volta-se para a satisfação das necessidades vitais, não sendo durável na medida em que o produto é consumido imediatamenta após o fim da atividade; a obra ou fabricação tem como fim a criação de objetos duráveis, a construção de um mundo artificial destinado a transcender até mesmo a vida dos produtores; a ação, por sua vez, é a única atividade que não está direcionada para a produção de objetos, sendo desenvolvida entre os homens, justamente pelo fato de homens, e não o Homem, viver na Terra. Cabe lembrar que enquanto o trabalho e a fabricação são realizados na esfera privada, a ação só surge na esfera pública. Sobre o tema, ver: (ARENDT, 2005a), (MAGALHÃES, 1985). 
te, a partir do conceito amoral de virtù de Maquiavel, como performance, bem como necessita de uma "audiência" e de um espaço para que o "espetáculo" possa se realizar, nas palavras de Arendt, a pólis grega foi "uma espécie de anfiteatro onde a liberdade podia aparecer" (ARENDT, 2001, p.201).

O fato é que se a ação política fosse produto da fabricação, se, no sentido Aristotélico, fosse poiesis e não práxis, ${ }^{4}$ se tivesse um objetivo exterior à mesma, criando assim um resultado que passaria a ter existência por si próprio, não dependendo mais do processo produtivo que o gerou, tal como as obras de arte, não haveria necessidade de novas ações, de constante recordação, de reencenações do momento inicial para a manutenção das próprias intituições políticas, sendo então necessário termos sempre em mente que "as instituições políticas são manifestações e materializações do poder; petrificam e decaem quando o poder vivo do povo cessa de lhes sustentar" (ARENDT, 2004b, p.120). Nessa linha, podemos dizer, seguindo os passos de Arendt, que a estabilidade e permanência de Roma foi ocasionada pela autoridade atribuída à fundação, autoridade esta que se baseava na continuidade de uma tradição, "na vitalidade do espírito da fundação" (ARENDT, 1988, p.161), e que pode ser visualizada no fato de todas as inovações e mudanças subseqüentes terem sido consideradas como desenvolvimento e aumento do ato inaugural. Isso explica o fato das guerras romanas não propugnarem o extermínio dos vencidos, mas sim a formação de parceiros, a transformação, através de acordos e alianças, dos inimigos em amigos, o que só contribuia para ampliar a República.

O que é importante ser ressaltado aqui é que a ação política enquanto fundação em Roma também significava liberdade, pois nada mais era do que um início, um novo começo ao qual se vinculavam todos aqueles que ainda viriam ao mundo. È justamente essa experiência política romana que está por detrás de uma outra noção de liberdade, não mais como interioridade, exposta por Agostinho em "A Cidade de Deus". Assim, segundo tal filósofo cristão, cada homem que nasce é um novo começo no mundo, e não do mundo, representando então a natalidade a possibilidade de surgimento do novo, o que leva Arendt a afirmar que a liberdade foi criada com o próprio homem, e por ser ele um início, é também o iniciador.

Essa identificação entre ação política e liberdade pode ser constatada através das próprias palavras que em grego e em latim era utilizadas pela designar a ação. Como bem lembra Arendt, em grego havia archein, que

4 "É por meio de uma reinterpretação violenta da categoria de práxis como energeia que Arendt extrai a ação política da trama teleológica em que Aristóteles a havia inserido, tendo em vista recuperar a dignidade e a autonomia da ação e do discurso políticos como 'fins' em si mesmos" (DUARTE, 2000, p.222, grifo nosso). 
significava "começar", "ser o primeiro" e, "governar" e prattein, cujo sentido era "atravessar", "realizar" e "acabar"; em latim, por sua vez, de maneira correlata, temos agere, que significava "pôr em movimento", "guiar" e gerere, cujo significado era "conduzir". Nas palavras de Arendt, é "como se toda ação estivesse dividida em duas partes: o começo, feito por uma só pessoa, e a realização, à qual muitos aderem para <<conduzir $>>$, <<acabar $>>$, levar a cabo o empreendimento" (ARENDT, 2005a, p.202). Resta então dizer que o que pretendemos enfatizar ao analisar o conceito de política para Hannah Arendt é que a mesma implica não só a possibilidade, latente em todos os seres humanos, de "começar", de criar algo novo, fazendo surgir o insperado, o imprevisível, mas também, e não de maneira secundária, que a ação política nunca se realiza no isolamento, sempre é uma ação em conjunto, configurando um acordo entre iguais. Dessa forma, por mais que o início seja obra de um único indivíduo, há a necessidade de "outros" para que a ação seja concluída, havendo então uma complementariedade entre as dimensões agonística e consensualista da ação política em Hannah Arendt. Por conseguinte, a política, apesar de ser iniciada pela espontaneidade humana, surge como relação, ela existe entre homens, em outras palavras, não é da essência do homem, considerado isoladamente, ser um "animal político" como pensava Aristóteles, mas por viver num mundo plural, a presença, o olhar do "outro", é uma marca indelével do fenômeno humano, só podendo ser "apagada" em momentos de "delírio".

Percebe-se, a partir dessa segunda dimensão da ação, a importância da alteridade para que a ação seja concluída, dessa forma poderíamos afirmar que os feitos dos heróis gregos não seriam grandes sem Homero, sem os poetas que os pudessem tornar imortais, por isso a criação da pólis pode ser explicada por essa necessidade de "platéia", de "espectadores" para que os acontecimentos extraordinários, que nesse espaço político podiam tornar-se corriqueiros, não fossem esquecidos. Por outro lado, a ação como início, como manifestação do espírito agonístico dos gregos também nos ensina que correlata à ação política está a busca por distinção, isto é, a luta por reconhecimento da própria singularidade, pois, como diz Arendt, é na coragem de agir, de "aparecer" no espaço público, que o homem revela "quem é", que ele confirma a sua própria identidade, a imagem que possui de si mesmo. Sem essa dimensão compartilhada, sem esse "sexto sentido", esse sensus communis, não seria possível ao homem saber-se real, ou seja, ele não poderia confiar em seus sentidos sensoriais, em outros termos, não saberia se existe ou se não passa de um sonho, tal como colocou Primo Levi ao falar sobre os reflexos que o regime de segregação criado pelas leis fascistas impuseram a si por ser judeu, já que ele teria sido condenado a "viver num mundo só meu, um tanto apartado da realidade, povoado de racionais fantasmas cartesianos" (LEVI, 1988, p.11). 
Ocorre que, por vivermos em um mundo plural, não podemos prever plenamente as conseqüências de nossas ações, e isto não se deve a uma deficiência congitiva, mas sim a um certo grau de imprevisibilidade de toda ação, haja vista que, por estarmos inseridos em uma rede de relações, onde toda ação gera reações, não podemos saber integralmente qual o resultado do processo irreversível que desencadeamos no mundo. Por isso Arendt diz que apesar de agirmos, não somos os autores da história, pois o significado da mesma somente pode ser encontrado no "fim", isto é, de maneira retrospectiva por quem se dispõe a narrá-la. Nessa linha, podemos dizer que a constituição de nós mesmos, de nossa biografia, do sentido de nossa existência, bem como a constituição da comunidade política em que vivemos é uma atividade plural, que é incapaz de ser realizada solitariamente, pois a antes mencionada rede de relações que está por detrás dos negócios humanos não permite que realmente sejamos soberanos e onipotentes, confirmando-se então a natureza fantasmagórica do "poder-Uno" tal como coloca Claude Lefort (LEFORT, 1987, p.84).

Dessa forma, podemos dizer que ninguém governa sozinho, sendo que até mesmo aquele que se utiliza da violência, que governa através de implementos, precisa de uma certa organização, do apoio de outros para a implementação de seu objetivo, nas palavras de Arendt, diríamos que mesmo "o mandante totalitário, cujo maior instrumento de domínio é a tortura, precisa de uma base de poder - a polícia secreta e sua rede de informantes" (ARENDT, 2004b, p.128), o que significa dizer que a violência, apesar de ser uma variável que não pode ser ignorada, não é um operador universal, não sendo suficiente para constituir uma comunidade política. Como bem sabia Maquiavel (MAOUIAVEL, 2001, p.55-6), a violência pode destruir o poder, a conquista pode desfacelar um regime de liberdade, mas não é capaz de construir nada, o que equivale a dizer que, ao contrário do que pensava Clausewitz, a guerra não é a "continuação da política por outros meios" (CLAUSEWITZ apud ARENDT, 2004b, p.98), haja vista que onde a violência prolifera o poder se esvai.

Ressalte-se, todavia, que dificilmente existirá a forma extrema do poder - Todos contra Um -, ou a forma extrema da violência - Um contra Todos -, o que ocorre é um movimento pendular de aproximação para cada uma das extremidades. Assim, para exemplificar, podemos citar as experiência totalitárias do século XX como ocasiões em que se pretendeu levar a violência a seu máximo, o que significava uma "morte" anunciada, pois na medida em que se progredia na destruição da própria base de poder, com a eliminação dos "amigos" e não só dos "inimigos", o que o regime estava fazendo era nada mais do que aniquilando a si mesmo. Percebe-se então que o terror totalitário, ao fazer com que o medo e a solidão atingisse a todos, até mesmo aqueles que os apoiavam, destruindo assim qualquer espaço co- 
mum, não estava fazendo nada além do que gerar instabilidade, do que disseminar "o germe de sua própria destruição" (ARENDT 2, p.530). ${ }^{5}$

Ocorre que, como bem sabia Arendt, a aniquilação do espaço comum iniciada com a atomização da sociedade de massas e potencializada com os regimes totalitários é concomitante com a eliminação dos parâmetros normativos que são configuradores do político, pois sem a mediação do Direito, enquanto liberdade e igualdade, só há poder que devora a si mesmo. Ressalte-se, todavia, que é a dimensão principiológica e simbólica do Direito que é automaticamente negada por um regime totalitário e que nos possibilita considerá-los como a perpetuação da exceção, haja vista que eventuais criações de leis positivas não conferem legitimidade aos regimes de terror, o que nos permite concluir que se não existe política tal como Arendt a concebe, tampouco há Direito nos regimes totalitários. Dessa forma, por mais que haja formalização jurídica em um regime totalitário, por mais que Hitler tenha chegado ao poder observando os procedimentos legais, tendo o partido nazista obtido aproximadamente 13 milhões de votos nas eleições de julho de 1932, por mais que tenha sido aprovada a denominada Lei de Autorização, que permitia ao gabinete governar em situações de emergência sem submeter seus atos à apreciação do parlamento, não podemos considerar, ao contrário do que pensava Kelsen, ${ }^{6}$ tal regime como um Estado de Direito.

O que podemos então constatar é que o regime que impeça a articulação de um mundo comum entre os indivíduos, mundo este configurador da política e do Direito, que pretenda a concentração do poder em uma só pessoa está fadado a entrar em crise, pois não há governo que permaneça sem

5 Essa dimensão autofágica também está presente na tirania, na medida em que o detentor do poder absorve para si todo o espaço público, aniquilando-o, permitindo aos indivíduos somente a satisfação de interesses privados. Ocorre que, como aparece no texto de Xenofonte sobre Hieron, o tirano, ao destruir o espaço comum, as mediações institucionais, legais, não tem a que recorrer para a garantia de seu próprio poder, daí a instabilidade de seu governo, cabendo ao mesmo, como fez Hieron ao falar de seu ofício como uma carga, defender, no âmbito privado, seu próprio poder da cobiça dos demais, pois o tirano é aquele que consegue realizar todos os desejos dos particulares (BIGNOTTO, 1998, p.169-75), (STRAUSS, 1988, p.95-133). De forma contrária, podemos lembrar a estabilidade do regime criado por Sólon, o que só foi possível ao se recusar a permanecer no poder, deixando vazio o lugar que temporariamente ocupou, do legislador, criando assim um governo de leis e não de homens (BIGNOTTO 1999). Não haveria então uma relação entre o poder como obrigatoriamente plural, no sentido arendtiano, e uma dimensão normativa asseguradora da desincorporação e continuidade desse poder?

6 Não obstante os escritos político-democráticos de Hans Kelsen, sua concepção do Direito como legalidade levou-o a afirmar o seguinte: "Segundo o Direito dos Estados totalitários, o governo tem poder para encerrar em campos de concentração, forçar a quaisquer trabalhos e até matar os indivíduos de opinião, religião ou raça indesejável. Podemos condenar com a maior veemência tais medidas, mas o que não podemos é considerá-las como situando-se fora da ordem jurídica desses Estados" (KELSEN 1996, p.44). 
uma base de sustentação, em outros termos, poderíamos dizer que mesmo que todos os homens se tornem "Um-Só-Homem" (ARENDT, 1990, p.519), que o governante se intitule o representante do "povo", procedendo a uma reificação do mesmo através da adoção do ideal de uma sociedade transparente, unificada, sem diferenças, sem conflitos, tal governo não passa de uma abstração, de um mito cujo trágico destino já está traçado, haja vista a artificialidade e "fragilidade" do "consenso" que o sustenta, pois este não está baseado em convicções, mas sim na vacuidade, na ausência do pensar, o que leva à submissão à regra pela regra, a uma absolutização da lei, que se for radicalmente alterada em caso de eventual mudança de regime, provavelmente levará consigo o apoio dos adeptos do regime anterior. Nas palavras de Arendt,

(...) todas as nossas experiências nos dizem que precisamente os membros da sociedade respeitável, aqueles que não tinham sido afetados pela comoção intelectual e moral dos primeiros estágios do período nazista, foram os primeiros a se render. Eles simplesmente trocaram um sistema de valores por outro. Diria que, portanto, os nãoparticipantes foram aqueles cuja consciência não funcionava dessa maneira, por assim dizer, automática - como se dispuséssemos de um conjunto de regras aprendidas ou inatas que aplicamos caso a caso, de modo que toda nova experiência ou situação já é prejulgada, e precisamos apenas seguir o que aprendemos ou o que possuímos de antemão. (ARENDT, 2004a, p.106-7)

É justamente a capacidade de pensar, a possibilidade de realização do diálogo interno consigo mesmo que acreditamos estar por detrás do"sentimento de legalidade" (ARENDT, 2004a, p.103) que emana daqueles que se colocam contra a "lei" de seu país em situações limite, como ocorreu com os irmãos Scholl e demais integrantes do denominado grupo "Rosa Branca", que ousaram se expor, posicionar-se, assumindo a responsabilidade pelo sim ou não diante do momento histórico em que estavam inseridos, editando planfetos de repúdio ao regime nazista, postura esta cuja recordação somente nos revela que a ação política como liberdade não é uma utopia, mas uma possibilidade sempre aberta, sendo esta a "promessa da política" (ARENDT, 2005).

Se todos, e não somente os "especialistas", como ressalta Arendt, somos capazes de pensar, somos também capazes de fazer "milagres", de realizar o imprevisível, o improvável, ou seja, somos todos maiores e portanto responsáveis até mesmo pela ausência de ação, pela servidão voluntária a que porventura tenhamos submetido a nós mesmos, o que demonstra que pensar e ser livre é uma questão de escolha, de coragem de se valer do próprio entendimento, como diria Kant (KANT, 1974, p.100), cabendo a tão-somente a nós, enquanto sujeitos marcados pelo devir, refutar o argumento do 
Grande Inquisidor de Dostoyesvski de que seja desejo eterno e unânime da Humanidade encontrar alguém diante do qual se curvar.

Dessa forma, a política, tal como Arendt a entende, como criação do novo, do inesperado, como ação plural, resultado do amor ao mundo e não como violência, não somente se apresenta como uma alternativa, como algo realizável, sendo inerente à condição humana, mas também representa uma necessidade, pois é condição para a constituição do indivíduo e da comunidade político-jurídica na qual nos movemos, haja vista que o reconhecimento do outro em sua diversidade não somente repercute na confirmação do sentido da minha vida, mas antes é essencial para a existência daquilo que me transcende, que me precedeu e que provavelmente não desaparecerá após o meu "fim".

Em outros termos, o mundo comum, as instituições, o Direito, tudo aquilo que pretende realizar a mediação entre homens, erigindo mais pluralidade e menos deserto, mais compartilhamento do que isolamento, só pode ser construído se a política for sinônimo de liberdade.

TORRES, Ana Paula Repolês. The sense of politics in Hannah Arendt. Trans/Form/ Ação, (São Paulo), v.30(2), 2007, p.235-246.

- ABSTRACT: Based upon Hannah Arendt's thought, we aim to demonstrate that political action is not the means to an end, but a synonim of "freedom". From this starting point, the author remarks the traditional identity between politics and violence, through a critical approach of the identity - found in the very beginning of phylosophical thought of the question - between freedom and will, that is, the desire to do what we want. In this way, Arendt is able to work two dimentions of political action, the agonistic dimention and the consensual dimention, defining the latter as mutually guaranteed freedom.

- KEYWORDS: politics; freedom; violence; plurality.

\section{Referências bibliográficas}

ARENDT, Hannah. Da Revolução. Trad. Fernando Dídimo Vieira. São Paulo: Editora Ática, 1988.

Origens do Totalitarismo: anti-semitismo, imperialismo e totalitarismo. Trad. Roberto Raposo. São Paulo: Companhia das Letras, 1990.

A Dignidade da Política: ensaios e conferências. Trad. Helena Martins e outros. Rio de Janeiro: Relume-Dumará, 1993.

A Vida do Espírito. Vol. II - Querer. Lisboa: Instituto Piaget, 1999a.

Eichmann em Jerusalém: um relato sobre a banalidade do mal. São Pau-

lo: Companhia das Letras, 1999b. 
ARENDT, Hannah. Entre o Passado e o Futuro. Trad. Mauro W. Barbosa de Almeida. 5.ed. São Paulo: Editora Perspectiva, 2001.

Responsabilidade e Julgamento. Trad. Rosaura Eichenberg. São Paulo: Companhia das Letras, 2004a.

Crises da República. Trad. José Volkmann. 2.ed. São Paulo: Editora Perspectiva, 2004b.

A Condição Humana. Trad. Roberto Raposo. 10.ed. Rio de Janeiro: Forense Universitária, 2005a.

. The Promise of Politics. New York: Schocken Books, 2005.

O Que é Política? Trad. Reinaldo Guarany. 6.ed. Rio de Janeiro: Bertrand Brasil, 2006.

ARRUDA, José Maria. Carl Schmitt: Política, Estado e Direito. OLIVEIRA, Manfredo. AGUIAR, Odilio Alves. SAHD, Luiz Felipe. (Org.). Filosofia Política Contemporânea. Petrópolis: Vozes, 2003. p.56-86.

BIGNOTTO, Newton. O Tirano e a Cidade. São Paulo: Discurso Editorial, 1998.

A Solidão do Legislador. Kriterion. Belo Horizonte, n.99, p.7-37, jun, 1999.

MORAES, Eduardo Jardim (Org.). Hannah Arendt: diálogos, reflexões, memórias. Belo Horizonte: Ed. UFMG, 2003.

DUARTE, André. O Pensamento à Sombra da Ruptura; política e filosofia em Hannah Arendt. São Paulo: Paz e Terra, 2000.

GUENIFFEY, Patrice. La Politique de la Terreur. Violence e terreur. Paris: Gallimard, 2000. p.19-42.

HABERMAS, Jürgen. Facticidad y Validez: sobre el derecho y el Estado democrático de derecho en términos de teoría del discurso. Trad. Manuel Jiménez Redondo. Madrid: Trotta, 1998

KANT, Immanuel. Resposta à pergunta: Que é 'Esclarecimento'? KANT, Immanuel. Textos Seletos, Edição Bilíngüe. Trad. Floriano de Sousa Fernandes. Petrópolis: Vozes, 1974. p.100-17.

Crítica da Razão Prática. Trad. Valerio Rohden. São Paulo: Martins Fontes, 2002.

KELSEN, Hans. Teoria Pura do Direito. Trad. João Baptista Machado. São Paulo: Martins Fontes, 1996.

LEFORT, Claude. A Invenção Democrática: os limites do totalitarismo. 2.ed. Trad. Isabel Marva Loureiro. São Paulo: Editora Brasiliense, 1987.

Pensando o Político: ensaios sobre democracia, revolução e liberdade. Trad. Eliana M. Souza. Rio de Janeiro: Paz e Terra, 2001.

LEVI, Primo. É isto um Homem? Trad. Luigi Del Re. Rio de Janeiro: Rocco, 1988.

LÖWY, Michael. Walter Benjamin: Aviso de Incêndio. Trad. Wanda Nogueira Caldeira Brant. São Paulo: Boitempo, 2005.

MAGALHÃES, Theresa Calvet de. A Atividade Humana do Trabalho (Labor) em Hannah Arendt. Revista Ensaio. São Paulo, n.14, p.131-68, 1985. 
MAQUIAVEL. O Príncipe. Trad. Antonio D'Elia. São Paulo: Cultrix, 2001.

SOUKI, Nádia. Hannah Arendt e a Banalidade do Mal. Belo Horizonte: Editora UFMG, 2006.

STRAUSS, Leo. Restatement of Xenophon's Hieron. What is political philosophy? Chicago \& London: The University of Chicago Press, 1988. p.95-133. 